\title{
Medium temperature solar thermal installation with thermal storage for industrial applications
}

\author{
Mircea Bunea ${ }^{1}$, Alexis Duret ${ }^{1}$, Elimar Frank², Lionel Péclat ${ }^{1}$, Stéphane Citherlet ${ }^{1}$ \\ ${ }_{1}$ Solar Energy and Building Physics Laboratory, Avenue des Sports 20, $\mathrm{CH}-1400$ Yverdon-les-Bains, Switzerland \\ 2 Institut für Solartechnik SPF, Hochschule für Technik HSR, Oberseestr. 10, 8640 Rapperswil, Switzerland
}

\begin{abstract}
In 2012, COLAS, the worldwide leader in the bitumen and road coatings sector, has decided to equip one of its regional sites with a solar thermal installation for temperatures up to $200^{\circ} \mathrm{C}$. Coupled with a gas boiler, the solar collectors were installed with the dual purpose of meeting the thermal energy needs of a workshop building and to maintain two bitumen storage tanks above its melting point.

This article gives a short description of the heating system at this industrial site and of its operating modes. It also describes the numerical model developed for detailed system simulation. First simulation results give a low annual solar heat gain of $94.6 \mathrm{kWh} / \mathrm{m} 2$ which is 2.6 times lower than initial estimations. Further investigations will be performed during the ongoing project in order to optimize the solar heat gain and to identify the reasons for this unsatisfactory result.
\end{abstract}

Key-words: medium temperature applications, solar thermal collectors, thermal storage, bitumen, simulation

\section{Introduction}

In Europe, the industrial sector is responsible for $26 \%$ of the final energy consumption (Eurostat, 2013) which makes it an important player in the energy consumption and greenhouse gas emissions debate. Moreover, Werner, 2005 showed that, in european community (EU25) plus seven more countries (including Switzerland), $30 \%$ of the industrial process heat demand is lower than $100^{\circ} \mathrm{C}$ and $27 \%$ is between 100 and $400^{\circ} \mathrm{C}$, see Fig. 1 .

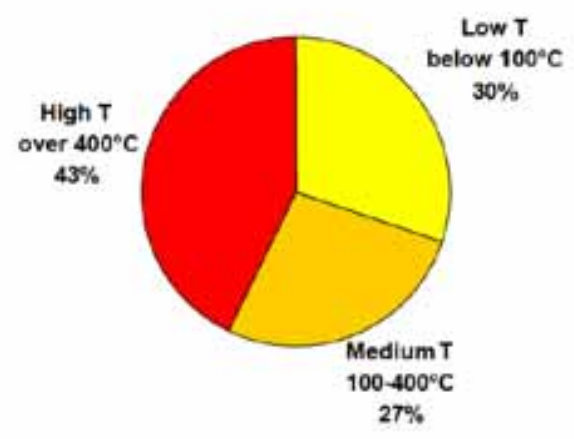

Fig. 1: Share of industrial heat demand by temperature level in the EU25 + Bulgaria, Romania, Turkey, Croatia, Iceland, Norway and Switzerland (Werner, 2005)

The industrial processes in the temperature range below $100^{\circ} \mathrm{C}$ are very suitable for the integration of wellestablished solar thermal systems. For higher temperature ranges, several new types of collectors have been developed recently (cf. Solrico, 2014). Currently, within the framework of the International Energy Agency (IEA) Solar Heating and Cooling (SHC) Task 49 (IEA-SHC, 2014) 134 solar thermal installations supplying process heat were reported worldwide, with a total capacity of about $100 \mathrm{MW}_{\text {th }}$ representing a very small fraction (less than $0.1 \%$ ) of the total solar thermal capacity installed. Those figures demonstrate that there is a considerable untapped potential for solar thermal energy in the industrial sector. 
Bitumen is needed for the road construction sector which is an industry based on fossil energy with important heat consumption in temperature range below $200^{\circ} \mathrm{C}$. Conscious of the important potential of the solar heat in its industrial process, but also of the economic and environmental issues related to fossil energy, COLAS Switzerland, plays a pioneering role in the integration of renewable energy at industrial sites. Thus, COLAS has implemented high temperatures solar thermal systems to maintain its bitumen tanks above $160^{\circ} \mathrm{C}$.

A first pilot project was launched on an asphalt production site in Geneva in 2011. This installation was designed to reduce energy consumption related to heating bitumen and implicitly, reduce emissions of greenhouse gases (Maranzana and Bornet, 2011). This first experience has shown that such a coupling is of real interest in reducing fossil energy consumption. On the other side, simulations showed that the annual performance of the solar thermal system could be significantly improved with a better orientation and tilt, lower operating temperature or shorter distance between solar collectors and bitumen tanks. Based on this experience, COLAS Switzerland has developed a second solar thermal system with several changes and more flexibility which was installed at a bitumen storage site in Yverdon-les-Bains (Switzerland). In both installations high vacuum flat plate collectors were used (see section with collector description in the following chapter).

During 2013, a R\&D project funded by the Swiss Federal Office of Energy was started aiming to analyze and optimize the thermo-economic and environmental performance of this installation, but also to evaluate the performance of energy storage in bitumen (Bunea et al. 2013).

\section{System description of the Yverdon plant}

At the site in Yverdon, COLAS stores bitumen used for road construction. The bitumen is delivered hot from the production plants and stored in two thermal insulated tanks. A gas boiler and a high vacuum flat plate solar collector field are used to maintain the temperature of the bitumen, in between 160 and $200^{\circ} \mathrm{C}$. In addition, the heating system delivers energy for space heat and domestic hot water (DHW) for a building located next to the facility. For this, a storage tank formerly used for bitumen is now being used as water storage. There are two operating seasons:

- April to September: "Summer season" - bitumen has to be provided and therefore stored between 160 and $200{ }^{\circ} \mathrm{C}$ permanently. Furthermore, DHW has to be provided to the office and workshop buildings on the site.

- October to March: "Winter season" - No bitumen is used. Only heat for space heating and DHW has to be provided.

Figure 2 shows the position of the various components on the site.

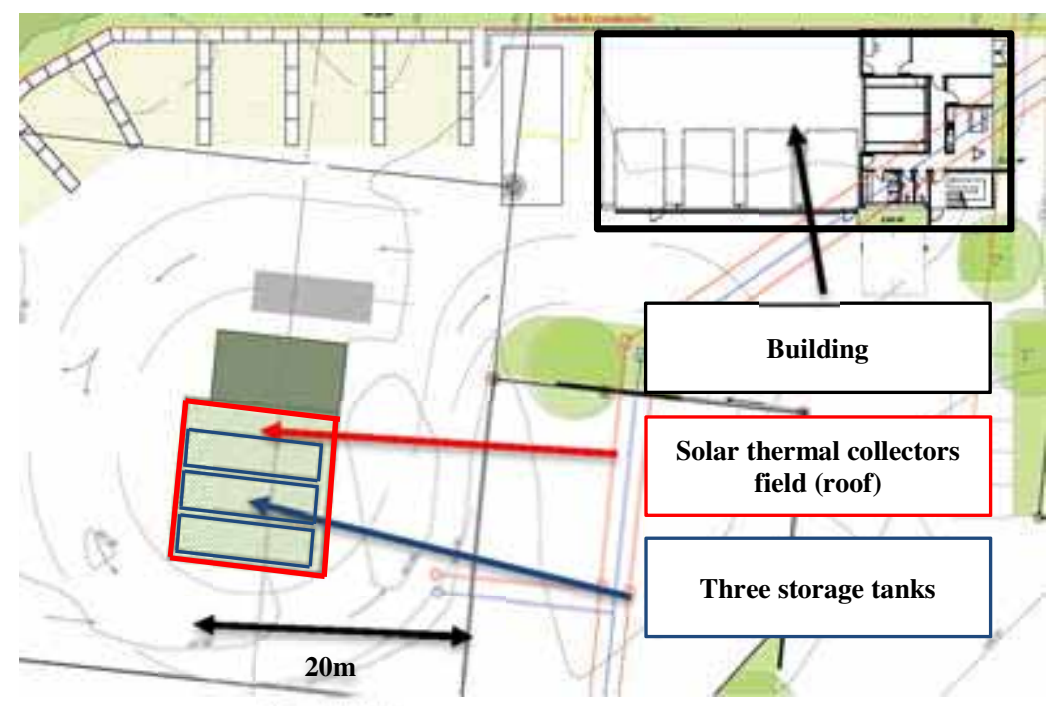

Fig. 2: Industrial site in Yverdon with the solar field location 


\section{a. Solar collectors}

The solar thermal collectors are manufactured by SRB Energy and were developed at the European Centre for Nuclear Research (CERN). The SRB Ultra High Vacuum (UHV) collector (Benvenuti, 2013) uses a technology based on a flat plate collector that can be combined with various mirror structures, which are a cost-effective way to increase the aperture area and to improve performance at high temperatures. For the Yverdon installation collector type $\mathrm{c} 2$ was chosen. The efficiency diagram of this collector can be seen in Figure 3.

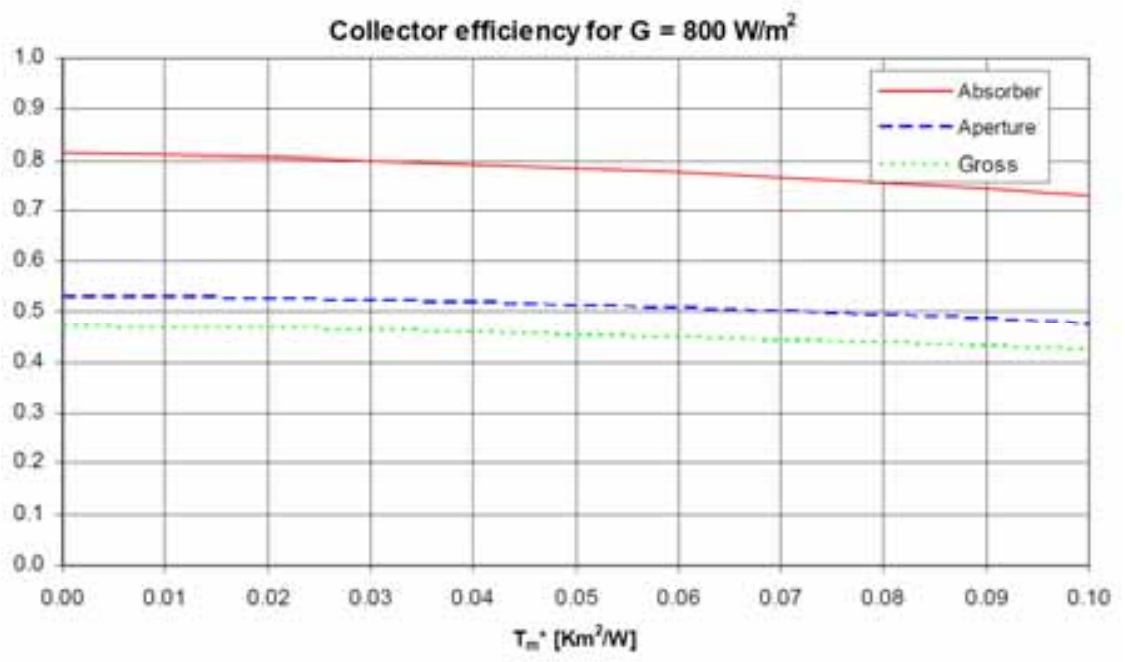

Fig. 3: Efficiency diagram for SRB UHV collector type c2 measured by SPF

These collectors are characterized by excellent thermal insulation provided by the high vacuum (10-8 mbar at ambient temperature) achieved and maintained using a Getter pump. This pump is activated by solar energy and it has the ability to remove air or any other gas molecules inside the collector through chemical reaction. This insulation combined with solar concentration allows the solar collector to reach a stagnation temperature of $400^{\circ} \mathrm{C}$, significantly greater than conventional solar thermal collectors. Moreover, compared to the "classic" concentration collectors that only use direct solar radiation, these collectors have the advantage to utilize a great part of the diffuse solar radiation, due to a larger absorber area. In Switzerland, the diffuse radiation is an important part of global solar radiation (more than 50\% for Yverdon-les-Bains climate) (Bunea et al, 2013).

On the Yverdon site the solar thermal field consists of 35 solar collectors spread over 7 rows of 5 collectors in series for a theoretical peak power of $96.1 \mathrm{~kW}$ with a solar irradiation of $1000 \mathrm{~W} / \mathrm{m}^{2}$. They are placed on a specially designed metal frame above the storage tanks, with an orientation of $50^{\circ}$ West and $20^{\circ}$ tilt. The heat transfer fluid (HTF) used in the system is a Shell mineral oil of type Thermia B supporting over $300^{\circ} \mathrm{C}$, without chemical or physical degradation.

\section{b. Storage tanks}

Three insulated storage tanks are presents on the Yverdon site. Two of the tanks are used for bitumen storage while the third is filled with water and serves as heat storage to meet the energy demand of the building. The water storage tank has a volume of $50 \mathrm{~m}^{3}$ and the bitumen storage tanks have a volume of $50 \mathrm{~m}^{3}$ and $70 \mathrm{~m}^{3}$, respectively. The bigger bitumen storage was installed in 2014 whereas the smaller one is old.

The thermal image of the three tanks (see Figure 4) shows the differences between the surface temperature of these storage tanks. Indeed, the old storage tanks thermal insulation is damaged and not very efficient and as a result it generates a lot more heat losses than the new one.

\footnotetext{
${ }^{1}$ http://www.spf.ch/fileadmin/daten/reportInterface/kollektoren/factsheets/scf1556en.pdf
} 


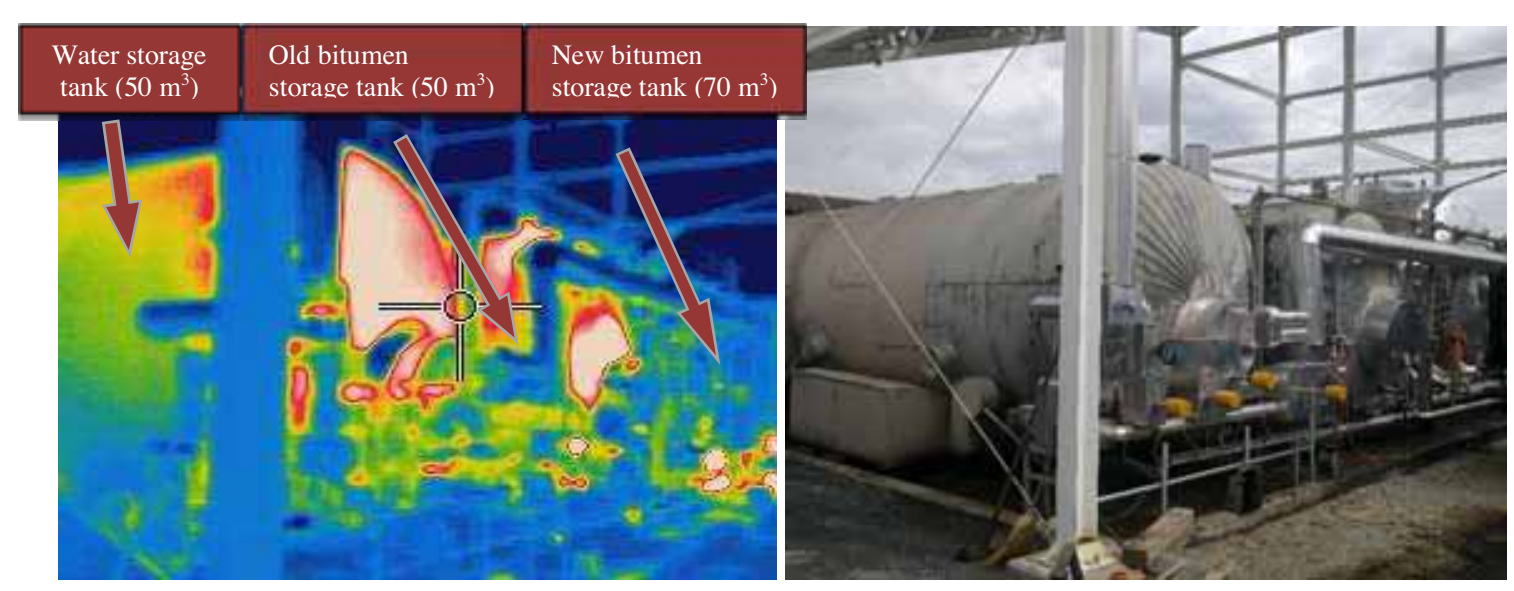

Fig. 4: Left: Thermal image of the three storage tanks; Right: Position of the three storage tanks

COLAS imagined to store solar heat at two temperature levels:

- The temperature of the water tank ranges between $60^{\circ} \mathrm{C}$ and $90^{\circ} \mathrm{C}$ depending on the weather conditions, but also on the building heat demand.

- The bitumen tanks are maintained at temperatures between $160^{\circ} \mathrm{C}$ (for bitumen viscosity reasons) and $200^{\circ} \mathrm{C}$ (thermochemical decomposition of bitumen beyond this temperature).

\section{c. Building}

The building was built in 2012. It was divided in two parts: a mechanical workshop with a heated volume of about $1500 \mathrm{~m}^{3}$ and a heated administrative part with a volume of $\sim 1200 \mathrm{~m}^{3}$; the administrative part is composed of two levels.

The energy consumption of the building is composed of space heat demand for the winter period and DHW demand for office employees and mechanics who take daily showers. The building heating annual energy demand was estimated by COLAS at $38^{\prime} 500 \mathrm{kWh}$. However, a more accurate determination of this consumption is necessary because of the use of the mechanical workshop. In fact, it has 4 large doors that are opened based on the workshop activities. The openings of these doors generate significant heat loss. Measurements during this project are expected to demonstrate the relevance of these estimations.

\section{d. Gas boiler}

When solar energy is insufficient, the energy demand for the building or to compensate the bitumen tanks losses is supplied by a gas boiler with a rated power of $250 \mathrm{~kW}$. This boiler was installed in 2013 and it replaces an old oil boiler with $1000 \mathrm{~kW}$ fixed power.

The boiler contains an important thermal oil storage which gives a large thermal inertia to the boiler. Although this energy stock generates heat losses, the burner operates mostly at reduced power and provides better overall performance compared to the old oil boiler. In addition, the natural gas operation will reduce the system emissions of greenhouse gases.

\section{e. System integration and regulation}

The solar installation can operate in different modes, being able to supply heat either to the water storage or the bitumen storage tanks depending on the heat demand of the site (see Figure 5).

- Summer season: If collector temperatures higher than $160{ }^{\circ} \mathrm{C}$ can be reached, solar heat is delivered to the bitumen tanks until the maximum temperature of $200{ }^{\circ} \mathrm{C}$ is reached. If the set point temperature of bitumen is reached, the water tank is loaded. Eventual surplus of solar heat can be stored in bitumen tanks.

- Winter season: During this season solar energy is delivered to the water tank to supply space heat and DHW demand. 


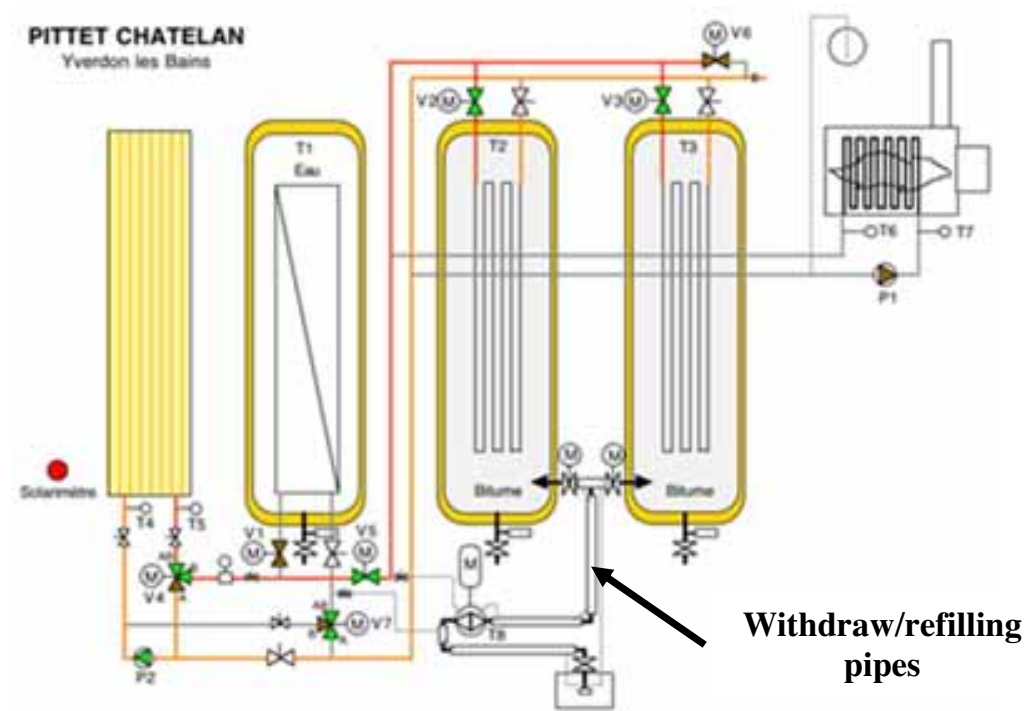

Fig. 5: Hydraulic scheme of COLAS system in Yverdon-les-Bains.

It has to be noticed that the withdrawing/refilling pipes of the bitumen tanks must be continuously maintained in temperature by solar energy or by the gas boiler, this to ensure availability of the introduction and removal of bitumen via tankers.

\section{Numerical modeling}

A simplified numerical model of the heating system was designed using the Polysun (version 7.0.7) software. The complexity of the installation does not allow the use of a standard model included in Polysun. Hence, a specific model was designed to reproduce the behavior of the installation in Yverdon-les-Bains and able to simulate its annual performance. This model will be then used later in this project to optimize the regulation procedure of the solar thermal system.

\section{a. Model overview}

Figure 6 shows the schematic diagram modeled with Polysun. Different elements can be distinguished:

- The solar collectors representing the field of 35 solar collectors SRB type c2;

- The water storage tank of $50 \mathrm{~m} 3$ for the on-site building energy needs;

- The bitumen storage tank of $120 \mathrm{~m} 3$ where the bitumen is stored and maintained in temperature;

- The building and the heating circuit simulating the energy consumption of the building;

- Two gas boilers integrated into each of the storage tanks.

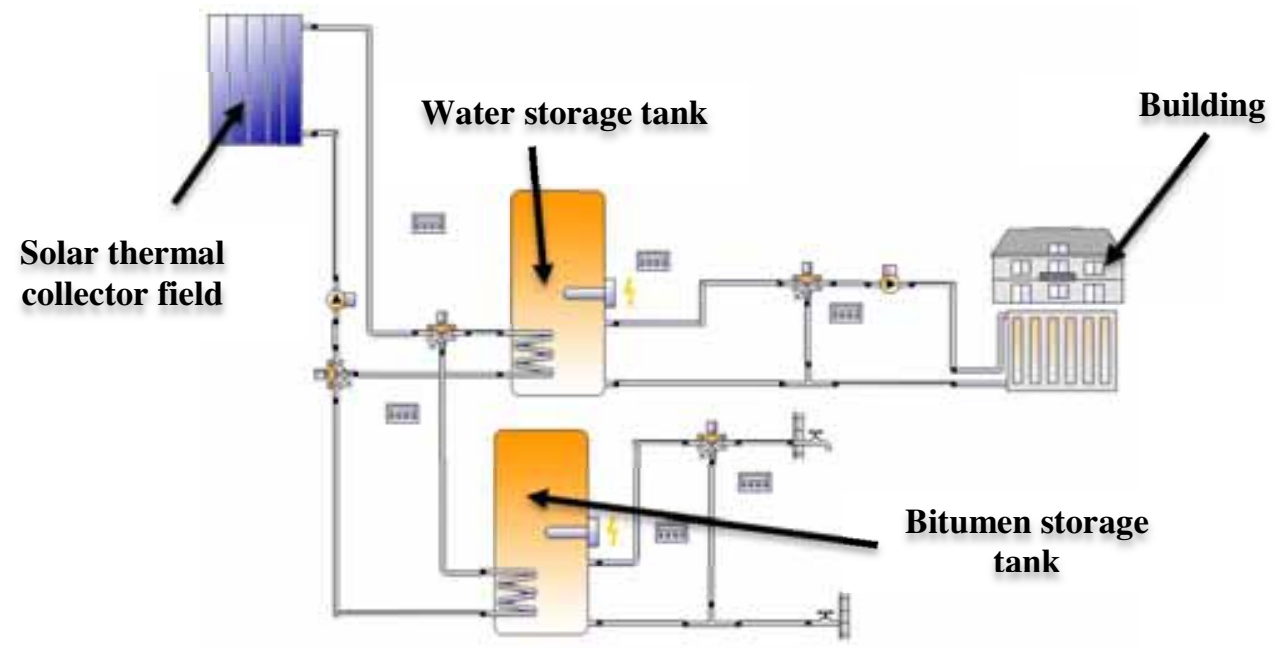

Fig. 6: Schematic diagram of the simulation model for COLAS installation in Yverdon-les-Bains. In the picture the symbols of heating rods are displayed, however, in the simulation the backup heating was realized using gas boilers. 
The climate of Yverdon-les-Bains is chosen from Polysun database for annual simulations, and the heat transfer fluid used is the Terminol SP with a flow rate of 2’300 1/h through the collectors. This fluid has similar properties with the fluid used in Yverdon-les-Bains system.

\section{b. Assumptions and simplifications}

\section{Solar collectors}

The collector model used in Polysun was provided on request by SRB Energy. This model is not present in Polysun database yet. The performance coefficients were estimated considering the experimental results for temperatures up to $100^{\circ} \mathrm{C}$. That being the case, this model should be validated for operating temperatures above $100^{\circ} \mathrm{C}$ up to $400^{\circ} \mathrm{C}$. The performance parameters used in the Polysun model are shown in Table 1

Tab. 1: SRB type c2 collector performance coefficients related to the gross area

\begin{tabular}{|lc|c|}
\hline \multicolumn{1}{|l|}{ Parameter } & {$[-]$} & Value \\
\hline no (optical efficiency) & {$\left[\mathrm{W} / \mathrm{m}^{2} \mathrm{~K}\right]$} & 0.47 \\
\hline a1 (heat loss coefficient) & {$\left[\mathrm{W} / \mathrm{m}^{2} \mathrm{~K}^{2}\right]$} & 0.19 \\
\hline a2 (temperature dependence on heat loss coefficient) & {$[\mathrm{J} / \mathrm{K}]$} & 0.0037 \\
\hline \multicolumn{2}{|l|}{ Thermal capacity } & 11300 \\
\hline
\end{tabular}

\section{Storage tanks}

Polysun is a simulation software used mostly for domestic installation where tanks are designed vertically. Therefore, a tank is set as a vertical cylinder and characterized by only two parameters: the height and the volume. In order to maintain the stratification and the total storage volume according to the installation in Yverdon-les-Bains where the tanks are placed horizontally, the same height and volumes were chosen as the real tanks.

The internal heat exchangers of the storage tanks are designed according to the existing heat exchangers of the system consisting of $57.4 \mathrm{~m}$ length of tube $(76 \mathrm{~mm}$ of external diameter) with a total heat exchange area of $13.7 \mathrm{~m}^{2}$. This value is 3 times lower compared to the general rule of thumb (e.g. Jobin, 1994) for conventional solar collector applications which suggests using $0.2 \mathrm{~m}^{2}$ heat exchange area for $1 \mathrm{~m}^{2}$ installed solar collector.

\section{Building}

The Polysun building module enables various settings based on information available to the user. The chosen parameterization is based on annual energy demand for heating (without DHW) and heat losses of the building. According to the heat balance provided by COLAS, the annual energy demand for heating is 38 '500 $\mathrm{kWh}$. The DHW consumption was calculated using the Swiss standard SIA 380.1, according to the floor area and the appropriation of the two parts of the building. Thus, according to the standard, the demand for DHW is 25 $\mathrm{MJ} / \mathrm{m}^{2}$ for both the mechanical workshop and the administrative part. With a gross floor area of $589 \mathrm{~m}^{2}$, the annual DHW demand reaches 14'725 MJ or 4,100 kWh. This amount of energy is distributed over the 12 months of the year and included in the space heating demand. This simplification is necessary because a second fluid extraction is not accepted by Polysun and a fluid is already defined for extractions of bitumen.

The building needs and heat losses are introduced in Polysun building model using monthly values and the yearly heat demand is resumed in Figure 7. 


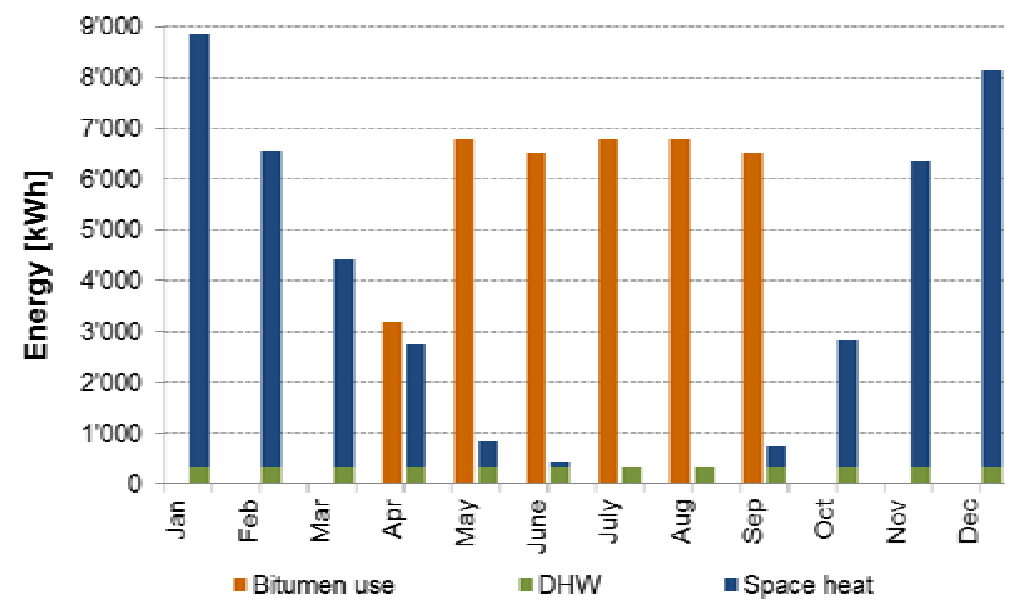

Fig. 7: Monthly load profile of Colas site in Yverdon-les-Bains.

\section{Gas boiler}

The modeling of the gas boiler and the hydraulic system related has been simplified. This element has been replaced with two integrated gas boilers placed within each of the two storage tanks (see Figure 6). This choice has as advantage to simplify the system control by removing the pump and piping components connecting the gas boiler to the storage tanks and should not affect the total fuel consumption. However, thermal losses due to fluid transport and the gas boiler oil storage will be evaluated and then taken into account.

\section{Bitumen load profile}

Polysun software is not designed to operate with tanks that are not fully filled with fluid. Consequently, the energy consumed by bitumen withdraws and refilling is simulated as first approach similar to a DHW loading profile. A constant inlet temperature of $100^{\circ} \mathrm{C}$ (maximum admitted by Polysun) is fixed while the outlet storage tank temperature is set to $160^{\circ} \mathrm{C}$. The amount of bitumen tapped every day varies every month according to the COLAS estimations for energy needed for bitumen used, cf. Figure 7.

\section{System regulation}

The regulation is modeled in accordance with the real system (see paragraph 2.e). In summer time, solar energy is delivered with a priority to the bitumen tank while the water tank is prioritized during winter time.

\section{c. First simulation results}

Figure 8 gives an overview of the monthly solar and gas consumption of the COLAS system. The high energy consumption in April is due to the fact that the bitumen is not heated during winter time and this energy is needed to heat up the bitumen that remained in the tanks from ambient temperature to $160^{\circ} \mathrm{C}$.

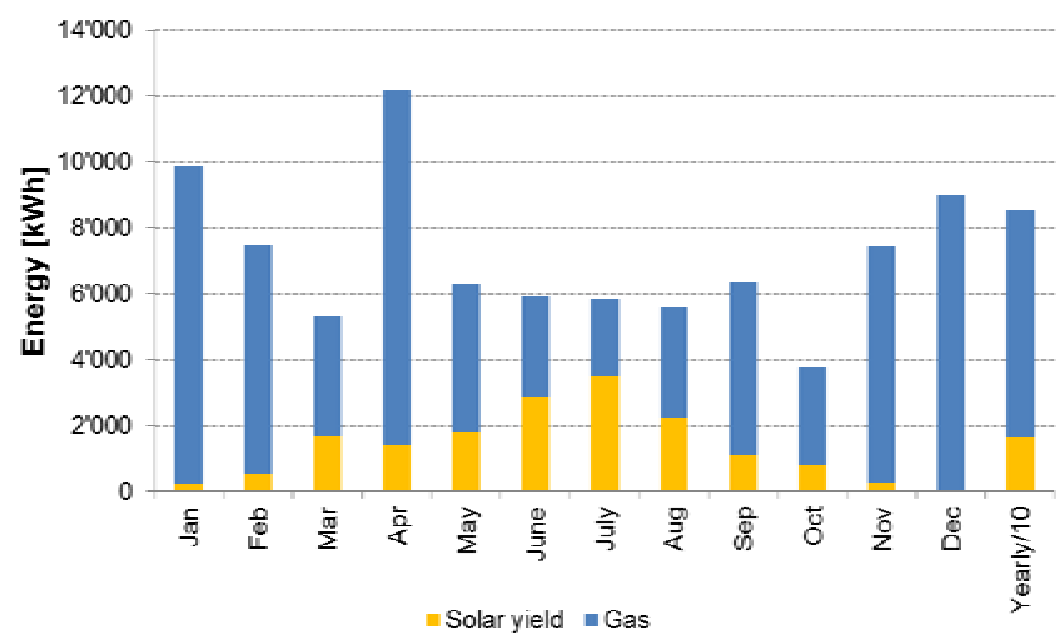

Fig. 8: Monthly contributions to the storage tanks. 
A heat balance for each of the two simulated storage tanks (bitumen and water) was performed separately considering the solar and gas contribution, energy consumption and heat loss.

Concerning the bitumen storage tank, a zoom was made for the months from April to September, as this tank is not heated for the rest of the year. The analysis of Figure 9 shows that even during the summer months, solar energy cannot supply all bitumen energy needs. Total solar energy yield during these months reaches 12 ' 822 $\mathrm{kWh}$, or $38 \%$ of the total energy necessary to maintain the bitumen in temperature.

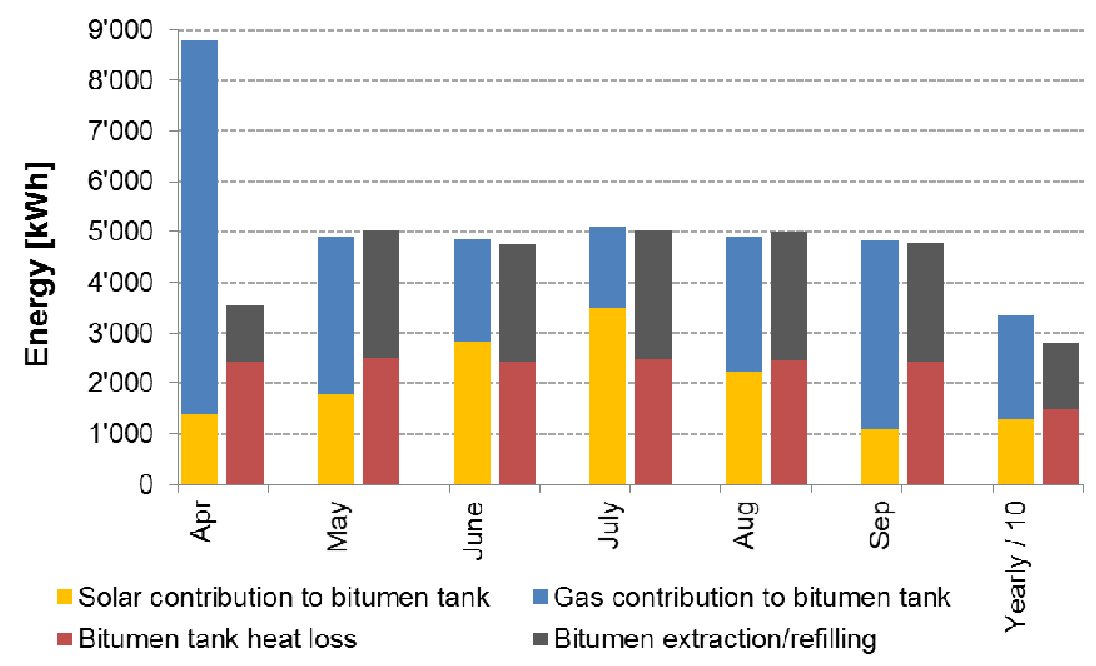

Fig. 9: Heat balance on the bitumen storage tank.

The analysis of the water storage tank (see Figure 8) shows that there is no solar heat available throughout period of April to September that exceeds the heating of the bitumen as solar energy is not sufficient to exceed the $190{ }^{\circ} \mathrm{C}$ in this tank. During the months from October to March, the total solar production energy yield is 3'570 $\mathrm{kWh}$, representing about $7 \%$ of total demand for the water tank.

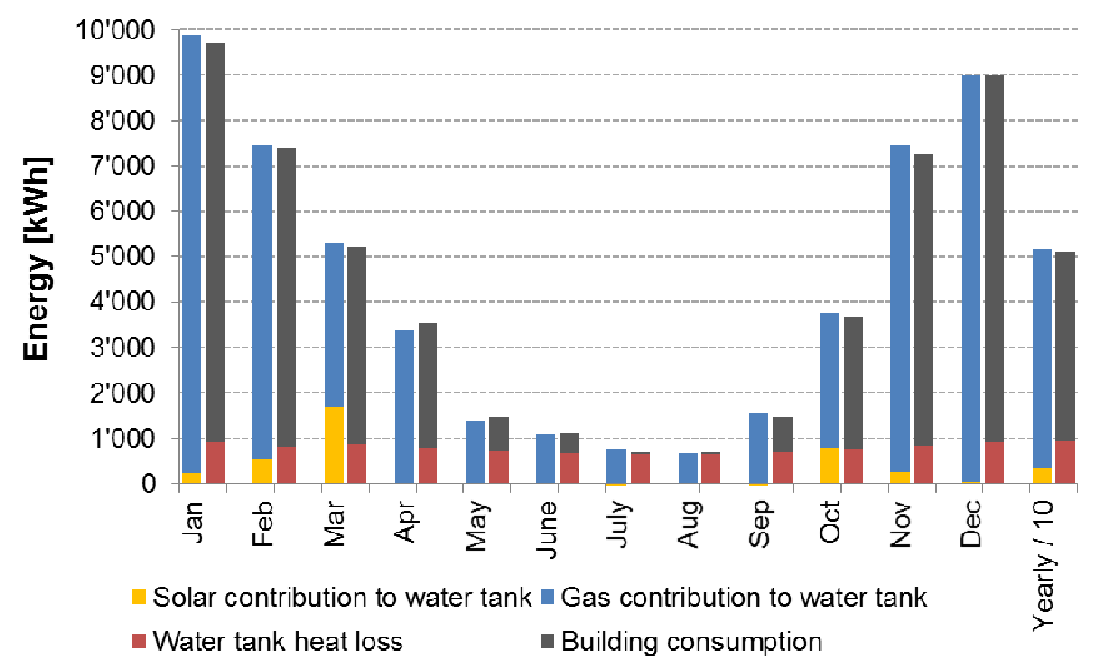

Fig. 9: Heat balance on the water storage tank.

Differences in energy balances appear in several months, especially during the months of July and August. These differences are explained by the fact of having included the DHW demand in the space heating demand. Thus, a part of the DHW needs can be compensated by the solar heat gain of the building. Still these differences do not affect considerably the annual results $(0.1 \%)$ and will be corrected when the model will be validated with the experimental results. 


\section{Discussion}

Overall, the solar productivity is relatively low, especially in winter time when solar gain is very limited for space heating and DHW even though the operating temperature level is quite low for this type of solar collector. The annual amount of solar energy reaches $94.6 \mathrm{kWh} / \mathrm{m}^{2}$ (relatively to the aperture area) for a total useful production of $16^{\prime} 392 \mathrm{kWh}$ and a solar system efficiency of $8.1 \%$. Several reasons were found to be responsible for this low solar performance:

- As described in chapter 3.b., the internal heat exchangers of the storage tanks are not properly dimensioned. A closer analysis revealed important temperature differences (up to $140^{\circ} \mathrm{C}$ ) between the solar collectors and the water temperature, see Figure 10. This leads to higher operating temperature of the collectors and implicitly to a lower performance.

- Attention should be paid to the HTF. Its thermal properties are not defined in detail in the Polysun database. Adding these parameters can also influence the simulation results (solar production increased of $44 \%)$.

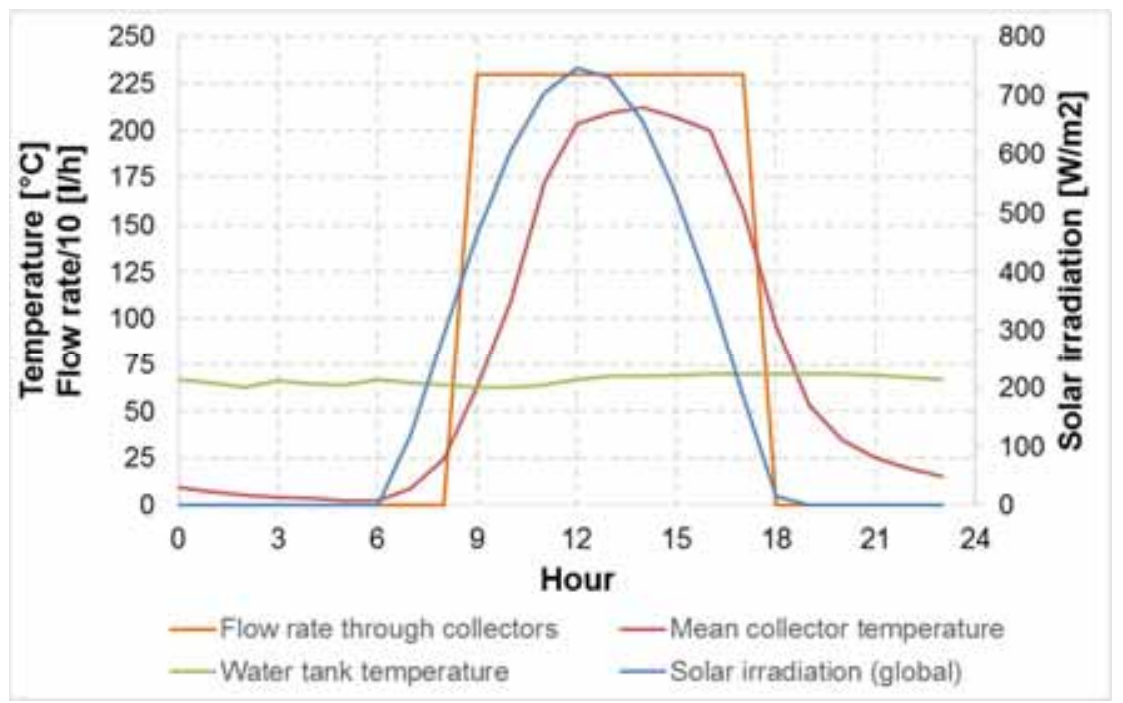

Fig. 10: Collector and water storage tank temperature (simulated) on $24^{\text {th }}$ of March.

In order to check these assumptions, a simulation was performed with several changes to the initial model:

- Internal heat exchangers with $40 \mathrm{~m}^{2}$ area (solar production increased of $13 \%$ );

- Doubled heat flow rate to $46001 / \mathrm{h}$ through solar collectors;

- The HTF chosen for the solar revolution was ANTIFROGEN SOL HT with modified boiling temperature at $350^{\circ} \mathrm{C}$.

Results with this modified model gives solar gains two times higher than the initial one

The solar collector behavior and IAM must also be validated under higher operating temperature. As an example, a simulation was performed with the SRB collector type $\mathrm{c} 1$ (which is theoretically less efficient than the c2) and the annual solar productivity increased to $216.4 \mathrm{kWh} / \mathrm{m} 2$. Nevertheless, the technical performance of the SRB UHV collector defined by parameters given in Table 3 and used by the simulation model are found to be very good for temperature ranges up to $200^{\circ} \mathrm{C}$ (up to $50 \%$ efficiency). Moreover, the inaccuracy of the IAM used for the simulation can be expected to be in the order of a few percentage points.

As this is not a standard simulation and many changes and simplifications had to be introduced for the simulations so far, the aspects mentioned will be further analyzed and simulation results will be validated with the experimental results. System regulation and more precisely the high set point temperatures for the storage tanks should also be investigated as $90^{\circ} \mathrm{C}$ for the building consumption is very high and bitumen might also be transferred from tanks under $190^{\circ} \mathrm{C}$.

Bunea et al. (2013) performed Polysun simulations with the same model collector and same IAM in order to evaluate the COLAS solar system potential in the climate of Yverdon-les-Bains. The solar plant was able to provide $15^{\prime} 090 \mathrm{kWh}$ at $65^{\circ} \mathrm{C}$ to the water storage during winter and $22^{\prime} 114 \mathrm{kWh}$ at $150^{\circ} \mathrm{C}$ in summer time reaching an annual solar yield of $214.7 \mathrm{kWh} / \mathrm{m}^{2}$. 


\section{Conclusions}

The potential of solar thermal systems in the industry has proven to be substantial and there is a growing need for reliable and cost-efficient systems in this area. This paper presents the integration of a medium temperature solar plant on an industrial site and the numerical modelling of this system. Solar energy was proven to be very suitable for road construction industry.

A numerical model was set up with Polysun in order to represent the behavior of the COLAS installation in Yverdon-les-Bains. Several assumptions and simplifications were necessary in order to fit this nonconventional model to the real system. Further investigations during the ongoing project are needed to validate this model.

Simulation results have shown annual specific collector yield of $94.6 \mathrm{kWh} / \mathrm{m} 2$ aperture area although a very efficient solar thermal collector is employed. This value is 2.6 times lower than initially evaluated by COLAS $(238 \mathrm{kWh} / \mathrm{m} 2 \mathrm{a})$, but it is comparable to the Geneva installation results where a yearly solar productivity of 93 $\mathrm{kWh} / \mathrm{m} 2$ has been reported (Maranzana and Bornet, 2011). A modified model with larger internal heat exchange area, higher flow rate and modified HTF points out that the solar production can significantly improve Therefore, it will be analyzed with the simulation model as well as measurements of the plant if and how the solar thermal system performance can be increased.

Even if the simulation model still needs improvements, this work revealed that gas consumption can be decreased on the Yverdon heating system with little effort by changing some of the system specifications that have been neglected during the planning phase:

- Reduce the set point temperatures for the storage tanks

- Enable solar heat to load the water tank in summer season if the bitumen tank has not reached the upper set point temperature, but collectors are above $60^{\circ} \mathrm{C}$

Solar thermal simulation represents a powerful tool for plant sizing, optimization and energy yield estimations. It also allows to explore sensitivity analyses on different design parameters. However, the model presented in this paper has to be validated with experimental results before performing further analysis.

\section{References}

Benvenuti, C., 2013. The SRB solar thermal panel

Bunea, M., Duret, A., Péclat, L., Bornet, P., Maranzana, M., Wendling, J.-B., Pauletta, S., Installation solaire à haute température de COLAS SA (Yverdon-les-Bains), 2013, Rapport annuel OFEN

Eurostat, 2013. Energy, transport and environment indicators. Luxembourg.

IEA-SHC 2014:

http://www.solrico.com/fileadmin/medien/pdf/World_map_of_solar_process_heat_collectors.pdf, accessed 20.08.2014.

Jobin, C., 1994 Production d'eau chaude solaire. Dimensionnement, montage, mise en service, entretien. Cours PACER

Maranzana, M., Bornet, P., 2011. Projet pilote de maintien en chauffe d'un stockage de 80'000 litres de bitume à $160^{\circ} \mathrm{C}$ par des panneaux solaires haute énergie, 2011, Rapport final OFEN

SIA 380/1:2009 L'énergie thermique dans le bâtiment

Solrico, 2014 :

http://www.solrico.com/fileadmin/medien/pdf/World_map_of_solar_process_heat_collectors.pdf, accessed 20.08.2014

Weiss, W., Mauthner, F., 2012. IEA-SHC, Solar Heat Worldwide - Markets and Contribution to Energy Supply 2010.

Werner, S., 2005. ECOHEATCOOL, The european heat market - Final report:

http://www.euroheat.org/Files/Filer/ecoheatcool/documents/Ecoheatcool_WP1_Web.pdf, accessed 20.08.2014. 